\title{
Mental Ability of Junior Secondary School Students in Basic Technology Multiple Choice Objective Test in Nigeria
}

\author{
Yinusa Akintoye Faremi, Ph.D \\ Akinwarere, Kehinde C. \\ Department of Guidance and Counselling, Faculty of Education \\ Adekunle Ajasin University, Akungba-Akoko, Ondo State, Nigeria \\ Fakolujo, Abayomi Babatunde \\ Department of Arts \& Social Science Education, Faculty of Education \\ University of Lagos, Akoko, Yaba, Lagos State, Nigeria
}

doi: 10.19044/ejes.v4no2a8 URL:http://dx.doi.org/10.19044/ejes.v4no2a8

\begin{abstract}
The study examined mental ability of Junior Secondary School Students in Basic Technology in Nigeria. The study adopted survey research design. The purpose of this study is to compare the mental abilities of junior secondary school students in basic technology in terms of age, sex and types of school (Urban and Rural). Two hundred students were selected from the target population in three senatorial districts of Ondo State using multi-stage sampling technique. Thirty multiple-choice objective test items were drawn from past questions in Junior Secondary School Basic Technology and administered on the selected students. One research question was raised, three hypotheses were formulated and tested at 0.05 alpha level. Data collected were subjected to descriptive and inferential statistics. Results of the analysis revealed that there was no significant difference between the performance of students between the age of 12-13, 14-15, and 15 years plus on basic technology multiple choice test. Also there was no significant difference between the performance of male and female students on basic technology multiple-choice test. Despite the fact that there was no significant difference between students performance in term of age, the mean value revealed that students at tender age (12-13 years) performed better than their counterparts who are older in age in basic technology multiple choice test. It was recommended among others that learning of basic technology and any other related subjects should commence from early stage of human development.
\end{abstract}


Keywords: Multiple-choice, Objective Test, Basic Technology, Mental Ability.

\section{Introduction}

Mental ability can be referred to as human intelligence or an individual ability to constructively solve problems in the environment without much instruction or assistance from another individual. Measurement of mental ability of students is a process of measuring the intelligence or cognitive ability of an individual because the brain has different compartments, each hogged to a specific ability upon which a test can be measured. The mental ability of any student can be measured by conducting cognitive ability tests. Cognitive ability tests assess abilities that involved thinking (e.g. reasoning, perception, memory, verbal and mathematical ability, and problem solving). Such tests pose questions designed to estimate applicants’ potential to use mental processes to solve work related problems or to acquire new job knowledge (U.S. Office of Personnel Management, 2016).

Traditionally, the general trait measured by cognitive ability tests is called ‘intelligence’ or ‘general mental ability’. However, an intelligence test often includes various item types which measure different and more specific mental factors often referred to as "specific mental ability".

Medical Dictionary (2016) viewed intelligence as an individual's ability to adapt and constructively solve problems in the environment. Wechsler (1939) cited in Medical Dictionary (2016) viewed intelligence not in terms of capacity, but rather in terms of performance since intellectual capacity cannot be seen nor its existence concretely verified and cannot be reliably measured but the achievement of any students can be reliably measured. Three scales on intelligence seemed to have been developed and subsequently revised by Wechsler to measure intellectual functioning of children and adult ability. These scales include:

i. Wechsler Adult Intelligence scale revised (WAIS-R) is designed for adults, age 16-74 years. The scale has eleven subtests which include information, digit span, vocabulary, arithmetic, comprehension, similarities, picture completion, picture arrangement, block design, object assembly and digit symbol;

ii. Wechsler Intelligence Scale for Children, third edition (WISC-III) is designed for children between age 7-15 years. The subsets of this scale include many of the same categories of subsets as the WAIS-R

iii. Wechsler Pre-school and Primary Scale Intelligence (WPPSI) is designed for children between age 4-6.5 years. The test is divided into six verbal and five performance subtests. The eleven subtests are presented in the following order. Information, animal house and 
animal house retest, vocabulary, picture completion, arithmetic, mazes, geometric design, similarities, block design, comprehension and sentences. (Medical Dictionary, 2016).

Another measuring scale for students' mental ability was designed by Stanford-Binet called Stanford- Binet intelligence test that was revised from the original Binet-Simon scale by Lewis M. Terman, a psychologist at Stanford University. The Stanford-Binet intelligence scale is now in its fifth edition (SB 5) and was released in 2003. It is a cognitive ability or intelligence test that is used to diagnose developmental or intelligence deficiencies in young children. The test measures five weighted factors and consists of both verbal and nonverbal subsets. The five factors being tested are knowledge, quantitative reasoning, visual-spatial processing, Working memory and fluid reasoning (Wikipedia Encyclopaedia, 2016).

Measurement according to Kizlik (2016) referred to measurement as the process by which the attribute of dimension of some physical object are determined. One exception seems to be in the use of the word measure in determining the IQ of a person. The phrase "this test measure IQ" is commonly used. Before the mental ability of any student can be determined a test must be conducted by an expert. A test can be defined as a task used to obtain systematic observations presumed to be representative of educational or psychological trait or attributes (Gilbert, 1974). It is also an instrument for measuring systematic sample of an aspect of human behaviour which includes performance, knowledge, achievement, intelligence, skill, personality and aptitude. Kolawole (2001) defined test as a specific instrument or systematic procedures for observing one or more characteristics of a student using either a numerical scale or classification scheme.

Test may be classified as individual and groups tests. verbal and non verbal tests, performance, and pencil and paper tests, teacher made and standardized tests. Tests can be used for selection, for placement, for diagnostic, to provide feedback or knowledge of results, as a source of motivation to improve programmes and curricula and for theory development. Pencil-paper test can be grouped into two, the essay test and objective test. Objective test is the type of test in which the candidate expects to select answer from limited options. The testee select "his wanted" answers from given option. According to Ogunmakin and Popoola (2003) objective test can be classified into two: the select types and the supply type. Alternate objective test can be regarded as the select types include multiplechoice, alternative response, matching, rank order, and pictorial while the supply types include short answer, complete, and association. Objective test is also a form of test constructed such that irrespective of who scores it, the score would be the same. The essay types of test are especially useful for 
measuring those aspects of complex achievement, which cannot be measured by objective tests. These include:

i. Ability to apply rather than merely identify, rotation and application of data and

ii. The ability to select, organize and integrate ideas in a general ways on a problem.

The junior secondary school in Nigeria shall be both pre-vocational and academic. It shall be tuition free, universal and compulsory. It shall teach basic subjects which will enable pupils to acquire further knowledge and skills (Federal Republic of Nigeria (FRN), 2004). For student to transit from the three years of Junior Secondary School to Senior Secondary School, he/she must register for the Junior School Certificate Examination (JSCE) conducted by the state Ministry of Education or National Examination Council (NECO) in Nigeria for candidates in the Federal schools, Arm Forces Secondary Schools and other Federal establishment operating secondary school. Private schools also take part in the state or NECO Junior School Certificate Examination (JSCE) provided that they are permitted by their Ministry of Education. A candidate is expected to sit for a minimum of ten subjects and a maximum of thirteen in which Basic Technology is one of the subjects offered by the students. In this examination, students are made to face little of short answer essay test and more of multiple choice objective test in nearly all the subjects examined.

\section{Multiple-Choice Objective Test}

Nworgu (1992) described multiple choice test items as a test that consists of a stem and a set of response alternative. The multiple-choice test items usually consists of two parts (i) The stem which may be called the stimulus statement and (ii) a list of four (4) or five (5) suggested responses or options in which one of the option called the correct answer is referred to as the "key". Other plausible answer except the key are referred to as distracters, wrong responses, decays or foils.

Multiple-Choice Questions (MCQs) are subset of what is referred to as 'objective questions'. These are questions which have one correct answer (usually only one). The term "objective"' here means there is complete objectivity in marking the test. The construction, specification and writing of the individual questions (items) are influenced by the judgements of examiners as much as in any other test. The answere to the items of the test are already predetermined before they are exposed to the testees.

Multiple-choice items are considered to be among the most versatile of all item types. They can be used to test factual recall as well as levels of understanding and ability to apply learning. Multiple choice can also provide an excellent basis for post-test discussion, especially if the discussion 
addresses why the incorrect responses were wrong as well. The correct responses were right. Unfortunately, multiple choice items are difficult and time consuming to construct (Ben and Esperanza, 2001).

In the present scientific and technological way, there is proliferation in the number of schools especially at the lower middle and upper primary schools I.e. junior secondary as a result of the need for more education for all school going age children worldwide, to meet the targets of the millennium development goals. The proliferation in the number of schools presupposes an increment in those that are located in the rural and urban areas (Bot, 2009). Daramola. (2009) explained that teaching and learning, whether is the rural or urban society, cannot take place in isolation. The increasing urbanization of societies has brought about a lot of challenges in the teaching and learning processes, there challenges notwithstanding, teaching and learning processes continues to benefit from ICT programmes.

In a research carried out by BOT (2009) revealed that the schools in rural and urban locations are underachieving in mathematics, the urban schools are doing better compared to the rural schools. He also stressed that rural students are behind urban students in mathematics achievement, which calls for effective teaching and learning of mathematics with emphasis on improving mathematics achievement especially among junior secondary schools students in rural areas.

\section{Science and Technology}

Science and technology merged in the pursuit of knowledge and solutions to problems that require the application of scientific understanding and product design. Solving technological problem demands scientific knowledge while modern technologies made it possible to discover new scientific knowledge. In a world shaped by science and technology, it is important for students to learn how science and technology connect with the demands of society and the knowledge of all content areas (Marine Department of Education Regulation 131, 2007).

A number of secondary school students have difficulties in their technology related subjects such as Basic electricity, Basic electronic, Building technology, Wood-work technology, Auto-mechanic, Technical drawing which lead to their poor performance in their Senior Schools Certificate Examination as a result of their deficiency in understanding the basic concept of basic technology at the Junior Secondary School level, this is not because they lack the aptitude but they have never acquired certain fundamental skill in basic technology. It is possible that the inability of the technical instructors or basic technology teacher to identify the difficulty level of the test and to examine the test item that can discriminate better between the upper and lower group students that took the test. It is possible 
that the inability of the students to relate what they have learnt in the classroom to real life situation or solves some practical problems in the basic technology could also be one of the contribution to the problem mentioned above which may negatively affect the performance of students' in basic technology.

Bamiro, Elekwa, Okolie, Onyedinma, Okorie \& Anyabolu (2001) stated that lack of proper technological orientation in our educational programme that is responsible for our great dependence on foreign technology, plant, machinery and man power. This is largely responsible for our huge external debt. The world has become a global village as we watch on our television sets events as they are happening in far and near places in the world. Machine has continued to replace human beings in place of work (Bamiro etal, 2001). Technology is a term that may be new to us but it is describing something which is not new at all. Technology affects our daily life. We see its effect around us everyday, even though we may not know what it is (Elekwa, Bamiro, Oluyide, Nurudeen, Akuru and Olopade, 2007). The scientific body of knowledge includes concepts, principles, facts, laws, ad theories about the way the world around us works. Despite the disasters caused by science and technology, their mistaken approach to the truth, and their failure to bring human happiness, they cannot be condemned outright and become pure idealists. Science and technology do not bear the full responsibility for humanity being devalued, thinking or reasoning being seriously weakened. (The Way to Truth, 2000).

The increasing focus on the development of conceptual understanding and the ability to apply science process skills is closely aligned with the emerging research on the theory of constructivism. Constructivism is the idea that learning is active process of building meaning for oneself. Thus, students fit new ideas into their already existing conceptual frame works (William, 2000). Some evaluators have not embark on the use of these conventional methods the educational reform movement has prompted school officials to turn to evaluation to answer the difficult questions about redesigning their vacation programmes at the state and local levels (Halasz, 1989). In order to know the level of recall of any students a test must be conducted. It is clear that technology means processes (methods) and products (materials) that make life easy and stress free (Elekwa etal, 2007). Developed technology involves the use of moderns and equipment to do things.

\section{Concept of Basic Technology}

Technology requires the use of human operators and understanding human capacities and limits essential for implementing technological advances. Nevertheless, psychology is often excluded from the list of core 
disciplines responsible for scientific and technological progress (American Psychological Association (APA), 2016). Science, technology, engineering and mathematics (STEM) initiatives in education and training enhance capital by providing:

i. Scientists and engineers who continue the research and development that is central to the economic growth of our country;

ii. Technologically proficient workers who are able to keep pace with rapidly developing scientific and engineering innovations and

iii. Scientifically literate voters and citizens who make intelligent decisions about public policy and who understand the world around them (APA, 2016).

Technology is the application of knowledge to the practical aims of human life or to changing and manipulating the human environment. Technology includes the use of materials, tools, techniques, and sources of power to make life easier or more pleasant work more and be more productive. While science concerned with how and why things happens, technology focuses on making thing happens (Webster, 2013). Nneji, Okon, Nwachukwu, David and Ogbuanya (2013). viewed technology as open knowledge or ideas, skills and procedures for making, doing or using things in specifiable and repeatable ways. Nowadays, it is technology that creates work to enable every person to have occupational calling and identify. In Nigeria, technology is raising the standards of living for all. Basic technology was organized around the following themes. You and Technology; Safety; Materials and Processing; Drawing Practice; Tools and Machine; Applied Electricity and Electronics; Energy and Power Maintenance; and Building (Nneji etal, 2013).

Introductory technology was changed to Basic Technology as a result of Basic Education Curriculum that was restructured for primary and junior secondary school in line with the Universal Basic Education (UBE) Programme by the Nigerian Educational Research and Development Council (NERDC). Introductory Technology is a pre-vocational subject offered at junior section of post primary education (Uwaifo, 2011). The main purposes of pre-vocational education previously referred to as and hence that of introductory technology include: requisition of basic technical skills, exposing students to career awareness by exploring understanding of the increasing complexity of technology.

Ivowi (1995) cited in Uwaifo (2011) stated that the following objectives of introductory technology are:

- to provide students with technology literacy required for everyday living 
- to provide pre-vocational orientation for future development of employable skills and training in technology

- to stimulate creativity.

The purpose of this study is to compare the mental ability of Junior Secondary Students in Basic Technology in term of age, sex and types of schools (urban and rural).

In attempt to measure the mental ability of Junior Secondary School Students in basic technology multiple-choice objective test, one research question was raised and three hypotheses were formulated and tested at 0.05 level of significance.

\section{Research Question one}

Is there any disparity in the performance of students within the age range of 12-13 years, 14-15 years and 15 years plus in basic technology multiple choice objective test?

\section{Research Hypotheses}

The following null hypotheses were formulated to guide the study: $\mathrm{H}_{01}$ : There is no significant difference between the performance of students between age of 12-13, 14-15 and 15 years plus in Junior Secondary School Basic Technology multiple-choice objective test.

$\mathrm{H}_{\mathrm{o} 2}$ : There is no significant difference between the performance of male and female students in Junior Secondary School Basic Technology multiplechoice objective test.

$\mathrm{H}_{03}$ : There is no significant difference between the performance of students from rural and urban junior secondary schools in basic technology multiplechoice objective test.

\section{Methodology}

The study adopted survey research design. The population for the study consisted of the entire Junior Secondary School (JSS) students in Ondo State, Nigeria while the target population consisted of the JSS III students preparing for the State Junior Secondary School Certificate Examination. Two hundred students were drawn from the public junior secondary school using multistage sampling technique. In the first stage, the state was categorised into three senatorial districts Ondo Centre, Ondo North and Ondo South using stratified random sampling technique. Each senatorial district consists of six local governments which consist a total of 18 local government areas in the state. In stage two, two local government were selected from each senatorial district to make a total of 6 local governments for the study using simple random technique. In stage three, one urban school and one rural school were selected from each of the two local 
governments selected for the study in Ondo Centre, Ondo North and Ondo South to make a total of six schools using simple random technique. In stage four, proportional stratified random sampling was adopted to select the 200 students for the study due to the existing number of arms and student in each school.

\section{Method of Data Collection}

Students were tested on the junior secondary school basic technology syllabus. The researcher prepared 30 items in basic technology selected from the 2012, 2013 and 2014 junior secondary school National Examination Council (NECO) past questions. The set of questions called multiple-choice objective test items of five (5) options were drawn from the past questions based on the syllabus of JSSIII and sampled all the various aspect of basic technology. The examinees were instructed to circle the correct key or answer inside the question paper. The 30 test items in basic technology were administered on the 200 students selected for the study for 45 minute under the supervision of basic technology teachers in each school selected for the study.

Research Question One: Is there any disparity in the performance of students within the age range of 12-13 years, 14-15 years and 15 years plus in multiple choice objective test items.

Table 1: Mean and standard deviation of multiple-choice

\begin{tabular}{|lrrrcc|}
\hline Format & & Age & N & Mean & Standard Deviation \\
\hline Multiple-Choice & $12-13$ & 78 & 37.61 & 4.38 \\
$14-15$ & 118 & 37.32 & 5.06 & \\
15 Plus & 4 & 36.50 & 4.12 & \\
Total & 200 & 37.42 & 4.77 & \\
\hline
\end{tabular}

From the result presented in table one, it showed the mean and standard deviation of the performance of Junior Secondary students in basic technology. Students that fall under 12-13 years of age in multiple-choice showed a mean of 37.61 and standard deviation of 4.38. For students within the ages of 14-15 years in multiple-choice test showed a mean of 37.32 and standard deviation of 5.06. For the students within the age range of 15 years plus in multiple choice showed a mean of 36.50 and standard deviation of 4.12.

\section{Hypothesis One}

There is no significant difference between the performance of students between the age of 12-13, 14-15 and 15 years plus in junior secondary school basic technology multiple-choice objective test. 
Table 2: ANOVA Summary of Students' Performance in Multiple- Choice by Age.

\begin{tabular}{|llcccc|}
\hline Source & SS & Df & MS & F & Sig \\
\hline Between Group & 7.496 & 2 & 3.748 & & \\
Within Groups & 0.163 & 0.850 & & & \\
Total & 4531.224 & 197 & 23.001 & & \\
& 4538.720 & 199 & & & \\
\hline
\end{tabular}

$$
\mathrm{p}>0.05
$$

Table two showed that there is no significant difference between the performance of students between age of 12-13, 14-15, and 15 years plus in multiple choice $(\mathrm{F} 2,197=0.163, \mathrm{P}>0.05)$. The null hypothesis is therefore not rejected.

\section{Hypothesis Two}

There is no significant difference between the performance of male and female students in junior secondary school basic technology multiplechoice objective test.

Table 3: $t$-test of students' performance in multiple choice objective test by gender.

\begin{tabular}{|lcccccc|}
\hline Group & $\mathrm{N}$ & Mean & SD & DF & t & P \\
\hline Male & 124 & 37.44 & 4.84 & & & \\
Female & 76 & 37.38 & 4.71 & & & \\
& & & & & & \\
\hline
\end{tabular}

$$
\mathrm{P}>0.05
$$

Table three showed that the t-cal. (0.089) is less than t-table value (1.960) at 0.05 alpha level. The null hypothesis is not rejected. This implies that there is no significant difference between the performance of male and female students on basic technology multiple-choice.

\section{Hypothesis Three}

There is no significant difference between the performance of students from rural and urban junior secondary schools in basic technology multiple-choice objective test.

Table 4: $t$-test of difference in the performance of students from rural and urban junior

\begin{tabular}{|lcccccc|}
\hline \multicolumn{8}{|c|}{ secondary schools basic technology } \\
\hline Group & $\mathrm{N}$ & Mean & SD & DF & t & P \\
\hline Urban & 124 & 34.81 & 4.82 & & & \\
Rural & -1.093 & 0.276 & & & & \\
& 76 & 35.57 & 4.68 & & \\
\hline
\end{tabular}


Table four showed that the students from rural Junior Secondary Schools had slightly higher mean in multiple-choice questions than the students from urban. However, the mean difference between the performance of the students from urban and rural junior secondary schools in basic technology multiple-choice questions is not statistically significant at $\mathrm{P}>$ 0.05 level $(\mathrm{t}=-1.093, \mathrm{P}>0.05)$. The null hypothesis is not rejected. This shows that students from both rural and urban junior secondary schools have the same potential towards the learning of basic skills in basic technology.

\section{Discussion of Findings}

The study revealed that the mean of the students' performance under the age of 12-13 and age of 14-15 years in basic technology multiple-choice formats is slight higher than that of the students under the age of 15 years plus which shows that students at tender age learn better than their counterparts who are older in age. This finding is not in agreement with the finding of Mathew (2014) which shows that older students recorded higher achievement in chemistry even though the average mean values do not vary widely. The findings of Ebenuwa-Okoh (2010) revealed that the younger students tend to be more focused on their academic pursuit than the older ones which are in conformity with the outcome of this study.

Despite the fact that the mean values of students within the age of 1213 years is slightly higher than the students within 14-15 and 15years plus it was revealed that there is no significant difference between the performances of student based on age. In a study carried out by Ebenuwa-Okoh (2010) on influence of Age, Financial status and Gender on academic performance among students, the result of the study revealed that there is no significant difference based on age. Also the finding of Ebenuwa-Okoh (2010) who found no significant difference between undergraduates academic performance based on age.

The study revealed that there is no significant difference between the performance of male and female students. The findings of Downing, Chan, downing Kwong \& Lian (2008) cited in Khawaileh and Zaza (2011) revealed the relationships between gender on a level scores and scores on the Learning and Study Strategies Inventory (LASSI) of undergraduates based on gender.

The study also revealed that there was no significant difference between the performance of students from rural and urban junior secondary schools. This study is not in agreement with the findings of BOT (2009) which revealed that the schools in rural and urban locations are underachieving in mathematics, the urban schools are doing better compared to the rural schools in mathematics. In a study carried out by Mathew (2014) which revealed that school location has significant effect on students 
achievement in chemistry which is not in conformity with the finding of this study that shows no significant difference between the performance of students from rural and urban in Introductory Technology.

\section{Conclusion}

The study established the mental ability of junior secondary school students in basic technology multiple choice objective test items. It was revealed that the mean of the students' performance under the age of 12-13 and age of 1415 years in basic technology multiple-choice formats is slight higher than that of the students under the age of 15 years plus which shows that students at tender age learn faster than their counterparts who are older in age in basic technology multiple choice test. This is an indication that young set of students assimilate faster than adult because they are not mentally occupied like adult. The study also concluded that there was no significant difference between the performance of male and female students. Moreover, the junior secondary school attended either urban or rural is not a determinant of students' performance in basic technology multiple choice test items.

\section{Recommendations}

The following recommendations were made to guide this study based on the findings of this study.

1. Learning of basic technology and any other related subjects should commence from early stage of human development since the study revealed that those students within the ages of 12-13 years and 14-15 years perform better than those students from 15 years plus.

2. During the teaching learning process, the teachers and instructors should not discriminate between male and female students. Teachers should have the belief that female students have the potential to acquire knowledge in basic technology like their male counterparts.

3. Students in both rural and urban schools should be exposed to the same technological skills that can develop their mental ability in developing the interest in studying engineering and technology courses within or outside Nigerian tertiary institutions.

\section{References:}

American Psychological Association (APA) (2016). Psychology as a core science, technology, engineering and mathematics (STEM) discipline. Retrieved from http://www.apa.org/pubs/info/reports/stem-discipline.aspx. Bamiro, O. A., Elekwa, I., Okolie, C. A., Onyedinma, A. C. B., Okorie, O. O. \& Angabolu, I. C. (2001). Introductory technology for schools and colleges student's Book2. Ibadan: Evans Brothers (Nigeria Publishers) limited. 
Ben, C. S. \& Esperanza, R. (2001). Is this a trick question? A short Guide to writing effective test questions. Kansas: Kansas Curriculum Centre Department of Education.

Bot, T. D. (2009). A comparative analysis of mathematics achievement in urban and rural junior secondary schools: A case study of Mangu. Nigeria Journal of sociology of Education, III (3), 105-117.

Daramola, C. O. (2009). Teaching and learning in urban society: The imperative of information and communication technology. Nigeria Journal of Sociology of Education, III (3), 36-43.

Ebenuwa-Okoh, E. E. (2010). Influence of age, financial status, and gender on academic performance among undergraduates. J. Psychology 1 (2): 99103

Elekwa , I., Bamiro, O. A., Oluyide, A. O., Ladoye, D. I., Nurudeen, A., Akuru, I. O. \& Olopade, O. L. (2007). Introductory technology for junior secondary school book 1. Lagos : Illus----EVAns Brothers (Nigeria publishers) limited.

Federal Republic of Nigeria (2004). National policy on education. Lagos: NERDC Press

Gilbert, S. (1974): Principle of educational measurement and evaluation. United State of America: Wad Worth Publishing Company.

Halasz, L. M. (1989). Evaluation strategic for vocation program redesign. ERIC Digests: ERIC Information Analysis Products (IAPS), 84.

Khwaileh, F. M. \& Zaza, H. I. (2011). Gender differences in academic performance among undergraduates at the University of Jordan: Are they real or stereotyping? College Student Journal 45 (3)

Kizlik, B. (2016). Measurement, assessment and evaluation in education. Retrieved from http://www.adprima.com/measuremnt.htm.

Kolawole, E. B. (2001). Test and measurement. Ado Ekiti: Yemi Prints and Publishing Services.

Marine Department of Education Regulation 131 (2007). Science and technology. Retrieved from https://www.marine.gov/education/ires/pei

Mathew, C. (2014). Learning strategies, age, gender, and school-location as predictors of students' achievement in chemistry in Rivers State. Research Humanities and Social Sciences 14 (21), 121-127. Retrieved from www.iiste.org.

Medical Dictionary (2016). Wechsler intelligence test. Retrieved from http://medical-dictionary.thefreedictionary.com/wechster+intelligence+test.

Nneji, O., Okon, E. J., Nwachukwu, V. C., David, N. A. \& Ogbuanya, T. C. (2013). Basic technology for junior secondary schools (Text Book 1). Lagos: learn Africa plc.

Nworgu, B. G. (1992). Educational measurement and evaluation theory and practice. Awka: Hallman publisher. 
Ogunmakin, A. O. and Popoola T. A. (2003). Introduction to test and measurement. Akure: Layo- Ola Printers.

The Way to Truth (2000). The concept of science and technology. Retrieved form www.thewaytothruth.org/science/tehnology.

U.S Office of Personnel Management (2016) Assessment selection other assessment methods-cognitive ability tests. Retrieved from https://www.opm.gov/policy-data-oversight/assessment-and-selection/otherassessment-methods/cognitive-ability-tests/

Uwaifo. V. O. (2011). Schools based approaches to skill identification models in introduction technology under the universal basic education (UBE) system in Nigeria. Journal of Research in Education and Society 2(1). Retrieved from www.kidr.org/.... /schools-

Webster, M. (2013). What is technology? Retrieved from www.cantechletter. com/2013/0

Wikipedia Encyclopaedia (2016). Stanford-Binet intelligence scales. Retrieved from https://en.wikipedia.org/wiki:/stanfors\%E2\%80\%93 Binetintelligence-scales.

William, B. (2000). Method of assessment Ohio: public schools in Cleveland 